\title{
Agentes Comunitários de Saúde: experiências e modelos do Brasil
}

I ${ }^{1}$ Maria Ruth Santos, ${ }^{2}$ Celia Regina Pierantoni, ${ }^{3}$ Lorena Lopes da Silva I

Resumo: O presente artigo é parte da tese de doutorado Perfil dos Agentes Comunitários de Saúde da Região de Juiz de Fora-MG e apresenta o perfil dos Agentes Comunitários de Saúde (ACS) sob a ótica das equipes de saúde da família, dos usuários e deles próprios. Discute os modelos e experiências sobre os ACS praticadas no Brasil antes da iniciativa do Ceará, na década de 80. Contextualiza os movimentos ocorridos para o sucesso da reforma dos ACS, que caracterizam um recurso humano central e estratégico para a implementação de ações de promoção da saúde, viabilizando o desenvolvimento de ações básicas voltadas para a comunidade. Demonstra que o agente comunitário de saúde constitui fator chave para viabilizar o apoio, a implementação e o desenvolvimento de ações básicas voltadas para a comunidade, de forma a expandi-las e a fortalecê-las em nível nacional, porém a promoção da saúde não concerne exclusivamente ao próprio setor e nem a um único profissional de saúde. Ela é resultado de ações intersetoriais, agindo nos determinantes gerais e da qualidade de vida.

> Palavras-chave: agente comunitário de saúde, agente de saúde, auxiliar de saúde.

\author{
1 Farmacêutica; doutora em \\ Saúde Coletiva, pesquisadora \\ visitante da Estação de Trabalho \\ IMS/UERJ da Rede Observatório \\ de Recursos Humanos em \\ Saúde. Endereço eletrônico: \\ maria.ruth@ims.uerj.br \\ ${ }^{2}$ Médica; doutora em Saúde \\ Coletiva, professora adjunta \\ do IMS/UERJ e coordenadora \\ da Estação de Trabalho IMS/ \\ UERJ da Rede Observatório \\ de Recursos Humanos em \\ Saúde. . Endereço eletrônico: \\ cpierantoni@gmail.com \\ ${ }^{3}$ Acadêmica de Enfermagem. \\ Bolsista da Estação de Trabalho \\ IMS-UERJ da Rede Observatório \\ de Recursos Humanos em \\ Saúde. Endereço eletrônico: \\ lorena.lopes.silva@gmail.com
}

Recebido em: 11/02/2010. Aprovado em: 22/08/2010. 
O Brasil, antes mesmo da realização da Conferência Internacional sobre Cuidados Primários de Saúde, que recomendou aos países a organização da atenção primária com participação comunitária enquanto parte de um sistema nacional de saúde, envolvendo médicos, enfermeiros, parteiras, auxiliares de enfermagem e agentes comunitários, já havia experimentado em serviços e programas nacionais ou locais a incorporação de auxiliares da própria comunidade nas atividades de assistência a indivíduos, grupos humanos e famílias.

A rigor, na história do processo de apropriação do saber e das práticas do campo da saúde pelas profissões institucionalizadas - notadamente, medicina e enfermagem - verifica-se que nas sociedades tribais e povos indígenas brasileiros, antes da colonização, o ato de saúde era exercido por um indivíduo especial, que desenvolvia um trabalho de característica globalizante - sacerdote, feiticeiro e pajé - membro da comunidade que respondia pelo diagnóstico, decisão terapêutica e preparo dos medicamentos. Esses praticantes são considerados os primeiros profissionais de saúde do Brasil e os primeiros agentes comunitários (PIRES, 1988). Com a colonização, a prática em saúde ganhou novos executores: os físicos, cirurgiōes, cirurgiōes-barbeiros, barbeiros, curiosos, algebristas, boticários, anatômicos, curandeiros, entendidos e outros (PIRES, 1988).

Praticamente até 1920, não existia no Brasil um órgão institucional responsável pela normatização ou definição de uma política de saúde para o país. O Centro de Saúde deveria aglutinar e coordenar as iniciativas e práticas sanitárias fundamentais, voltadas para uma região geográfica, com base populacional bem delimitada. Partiu-se do pressuposto de que o sucesso do projeto dependia da confiança que a comunidade depositasse no serviço. Nesse contexto, o Centro de Saúde foi definido como um local irradiador de influência e melhoria social em geral, revelando sua preocupação política com as questôes preventivas e educativas.

Surgia em torno dessa concepção um campo enorme de intervenção e preocupação com o indivíduo e sua comunidade. Outro elemento bem característico desta proposta de organização sanitária era a presença da enfermeira-visitadora, considerada elemento nuclear e primordial no trabalho sanitário. A visita domiciliar também já era praticada, no modelo campanhista, enquanto estratégia de assistência, desde a primeira década do século $\mathrm{XX}$, tendo sido utilizada tanto para campanhas como para saneamento e saúde, segundo paradigmas de saúde e de assistência distintos. 
Outro modelo de expansão e ampliação do atendimento em saúde que pode ser indicado como referencial importante foi o adotado pelo SESP, que existiu de 1942-1960, transformou-se em FSESP, de 1960 a 1990, tendo sido, com a reforma administrativa empreendida pelo governo Collor, extinta. Desde então integra, junto com a Superintendência Nacional de Campanha (SUCAM), um novo órgão denominado Fundação Nacional de Saúde, com sede em Brasília, responsável pelas questōes de saneamento, epidemias e endemias e saúde indígena.

Em 1942, o Brasil assinou convênio com o governo americano, representado pela Fundação Rockefeller, para sanear regiōes de extração de matéria-prima estratégica para os EUA durante a guerra (a Amazônia e o Vale do Rio Doce, por apresentarem altas taxas de malária e febre amarela, foram escolhidos para implantação inicial desses serviços médico-sanitários).

No final dos anos 40, o SESP começou expandir suas atividades em alguns estados brasileiros como Bahia, Pernambuco e Paraíba. A partir daí, iniciou-se um movimento de fusão e fortalecimento de seu modelo de atendimento, com concentração nas regiōes Norte e Nordeste do país, onde foi implantada a maioria de suas unidades sanitárias. A proposta pretendia alcançar todos os profissionais da unidade sanitária, envolvendo-os no exercício de práticas educativas, a começar pelo médico, que recebia o paciente para exame e que deveria iniciar o processo de educação.

Nos serviços do SESP, a enfermeira dividia as funções educativas com a visitadora sanitária e o auxiliar de saneamento. Competia às enfermeiras a supervisão e a orientação do trabalho das visitadoras, já que nesse período o número de enfermeiras diplomadas era insuficiente para realizar atividades de visita domiciliar. Seu papel como elemento de integração entre a comunidade e o serviço foi constantemente ressaltado. À visitadora sanitária, por sua vez, cabia uma relação mais estreita com as famílias do distrito onde trabalhava, exercendo funções que se tornavam mais complexas de acordo com o tipo de unidade onde estava inserida (BODSTEIN; FONSECA, 1989).

Podemos identificar no trabalho conjunto da enfermeira-visitadora, da visitadora sanitária e do auxiliar de saneamento, no aspecto da integração entre a comunidade e o serviço, algumas características de trabalho comunitário dentro de uma pequena localidade, com enfoque sobre a família, comunidade, e não sobre o indivíduo, que encontra similitudes com a proposta do PSF de 
1168 hoje e da atuação dos agentes comunitários de saúde, muito embora apoiadas por concepções de processos de saúde e doença distintas. A concepção presente no modelo sespiano é a que aborda a saúde como uma questão de bons hábitos higiênicos individuais ou, na melhor das hipóteses, de pequenos grupos, enquanto o conceito ampliado de saúde, o enfoque na integralidade da atenção e fortalecimento das ações intersetoriais, para colocar em prática novas estratégias de promoção da saúde, são os princípios valorizados pelo PSF e PACS.

Os princípios norteadores e as diretrizes estabelecidas pelo SESP certamente contribuíram para o surgimento de uma concepção e prática de saúde pública no país e têm grande importância na atualidade. Destaca-se, no trabalho do SESP, a similitude com os princípios e diretrizes hoje defendidas pelo PSF e PACS: a experiência com modelos de oferta organizada de serviços na unidade de saúde, no domicílio e na comunidade, a abordagem integral da família, a unidade de saúde indo à população, a adscrição de clientela, o enfoque intersetorial e a educação sanitária, como mola-mestra das ações.

Segundo Silva e Dalmaso (2002), na década de 70, após a eleição direta de prefeitos em cidades que não eram capitais, nem municípios estratégicos, proliferaram iniciativas locais para resolver demandas sociais emergentes e urgentes, sendo a saúde uma das áreas priorizadas. Vários municípios de Minas Gerais, Paraná e São Paulo implantaram projetos dentro dos princípios da atenção primária em saúde, incluindo o de agentes comunitários de saúde, surgindo, assim, o desenvolvimento de ações próximas às identificadas na atualidade, como sendo do âmbito de atuação dos agentes comunitários de saúde.

Os programas de saúde do Centro Executivo Regional do Vale do Jequitinhonha, em Diamantina, iniciados em 1971, e o Sistema Integrado de Prestação de Serviços de Saúde do Norte de Minas, em Montes Claros, em 1975, constituíram, nessa conjuntura, experiências originais e singulares de construção coletiva de um novo modelo de organização de serviços. No desenvolvimento desses programas havia, de um lado, as agências internacionais de saúde como a OPS, e de financiamento, como a Fundação Rockfeller, a Fundação Ford, o Banco Mundial e a Fundação Kellogg; e de outro, profissionais e intelectuais, dos Departamentos de Medicina Preventiva das Faculdades de Medicina (SANTOS, 1995).

Previa-se uma estrutura hierarquizada em quatro níveis: domiciliar, local, de área programática e de região, sendo os serviços distribuídos entre os quatro 
níveis. No mais simples, incluíam-se os domicílios, com ações preventivas, através de visitas domiciliares dos auxiliares de saúde e ações curativas, realizadas no sistema oficial. A ideia-motriz do projeto era a construção coletiva de um novo modelo de organização de serviços, que fortalecesse a autonomia do nível local. Com a introdução de inovadoras práticas de planejamento e gestão, esperavase transformar as relaçôes no interior da equipe de saúde, exercitando novas práticas pedagógicas, com valorização da participação cidadã da comunidade e dos servidores, visando à superação de todas as estruturas estabelecidas.

Selecionados entre moradores da comunidade, atuariam como agentes da participação popular nas decisões voltadas para alterações das relações do poder local. No entanto, por mais que a promoção da participação comunitária e o incentivo à organização das demandas concretas do setor saúde tenham sido claramente definidos enquanto missão institucional do projeto, na prática, verificou-se que alguns auxiliares de saúde não conseguiam coordenar uma efetiva mobilização e conscientização da população.

As atividades educativas desenvolvidas pelos auxiliares se organizavam em torno de orientação ao trabalho das parteiras, reforço ao uso da medicina popular caseira com a utilização dos chás, orientação alimentar utilizando os produtos da região, orientação em puericultura e amamentação natural, visita domiciliar, consultas coletivas, dentre outras. O programa visava a preparar pessoal de nível primário para executar ações, mediante um treinamento de seis meses, e pretendia atribuir a esse pessoal funções de diagnóstico e tratamento, o que "parecia ir contra o aspecto legal do exercício da medicina e também era um desrespeito àquela população pobre, pois então vamos oferecer um programa de saúde executado por pessoal sem nenhuma qualificação profissional para isso" entrevista com José R. Paiva, 09/07/93 (SANTOS, 1995, p. 44).

Van Stralen (1986) considera que, apesar da convivência, no projeto, de concepções que enfatizavam o caráter transformador do trabalho em saúde, na prática prevalecia a orientação da medicina tradicional na atuação dos auxiliares, que era reforçada pela visão do usuário de não valorização do trabalho preventivo e educativo, e sim do acesso à consulta e à receita médica. Em que pesem os problemas e dificuldades, o Projeto Montes Claros se transformaria, ao mesmo tempo, de imediato, no principal modelo para a montagem em nível nacional da primeira experiência de extensão de serviços de medicina simplificada para a 
zona rural já levada à prática no país - o Programa de Interiorização das Ações de Saúde e Saneamento (PIASS) - e, posteriormente, em referência de modelo para a reorganização dos serviços de saúde, constituindo-se em um marco inicial da Reforma Sanitária Brasileira.

O PIASS foi instituído inicialmente para a Região Nordeste do país, no período 1976-79, objetivando a estruturação de unidades de saúde pública em comunidades de até 20 mil habitantes, com utilização ampla de pessoal de nível auxiliar recrutado nas próprias comunidades a serem beneficiadas, para a execução de um conjunto de práticas sanitárias relacionadas ao meio ambiente e domiciliar e à atenção individual.

Para dar suporte à formação de recursos humanos requeridos pela nova política de atuação na área, voltada para a extensão de cobertura conforme necessidades e possibilidades de diferentes áreas do país foi criado, em 1975, pelo acordo de cooperação técnica entre o Ministério da Saúde (MS) e a Organização PanAmericana de Saúde (OPAS), o Programa de Preparação Estratégica de Pessoal (PPREPS), que ficou incumbido da preparação em larga escala, de pessoal de saúde de nível médio e elementar (BRASIL, 1976).

O modelo, construído através dos três projetos institucionais (PLUS, Projeto Montes Claros e PIASS), caracterizou-se como um modelo regionalizado, hierarquizado em quatro níveis assistenciais, com definição de porta de entrada para o sistema. Suas principais diretrizes eram: a universalização, a acessibilidade, a descentralização, a integralidade e ampla participação comunitária. A nosso ver, essas diretrizes e esse modelo continuavam a orientar todas as propostas que o movimento sanitário elaborou para o PREV Saúde, na VIII Conferência Nacional de Saúde e na Reforma Sanitária (ESCOREL, 1987, p. 48).

O Plano de Localização de Unidades de Serviço (PLUS), elaborado a partir de 1975 no interior do então INPS, foi desenvolvido a partir de um convênio com o IPEA entre 1976 e março de 1979, e teve como produtos os planos de saúde para sete regiōes metropolitanas e todo o estado da Paraíba.

O PIASS acabou por se expandir para todo o país e, em sua área de abrangência, foi incluído o Programa de Expansão de Serviços Básicos de Saúde e Saneamento, numa área rural, no Vale do Ribeira, São Paulo, ficando conhecido nacionalmente como Projeto DEVALE. Dentre outras estratégias, o projeto previa a extensão de atividades de assistência primária à população residente na 
periferia dos centros urbanos e na zona rural, mediante a instalação de postos de saúde operados por agentes, recrutados na própria comunidade.

Silva e Dalmaso (2002) identificam três componentes principais que deveriam integrar o conjunto de práticas do agente de saúde: o primeiro, mais teórico, relacionado ao desenvolvimento de atividades individuais, de atendimento a queixas ou problemas; o segundo, relacionado às atividades comunitárias, e o terceiro, referente ao modo como deveria ser desenvolvido o conjunto de atividades previstas nos dois componentes anteriores. A proposta de ação para o agente de saúde incluía a execução de curativos, vacinas, diagnósticos e tratamentos de doenças mais encontradas, atendimento à criança e à gestante, encaminhamentos, primeiros-socorros, adoção de uma visão global do indivíduo e seu papel na comunidade, condições gerais de vida da população e a organização da comunidade para lutar pela saúde.

Os agentes de saúde, além de terem sido indicados a partir de critérios estabelecidos pela comunidade, selecionados e recrutados nas localidades, apresentavam alguns traços comuns: já haviam desempenhado anteriormente funções similares àquelas esperadas e/ou já desenvolviam alguma ação comunitária nas igrejas, clubes de mães e de jovens, nas escolas comunitárias e nas associações civis, voluntárias e informais.

Para Silva (2001), o agente do DEVALE, por não dispor, na maioria das vezes, dos instrumentos básicos para o desenvolvimento das atividades para as quais estava sendo capacitado e por não encontrar espaço para discutir sobre o trabalho nas condições mais próximas onde o trabalho se desenvolvia, dificilmente poderia reproduzir as propostas que originaram o projeto e que nortearam seu treinamento. Por esses motivos, o esforço que fazia para manter o padrão de trabalho implicava frequentemente enorme desgaste profissional.

Numa tentativa de síntese dos projetos apresentados, destaca-se que o SESP teve origem num contexto de esforço de guerra e incorporou o visitador sanitário, recrutado dentre as pessoas do município que demonstravam interesse e possuíam segundo grau completo, para exercer atividades em visitas domiciliares e na comunidade. O PIASS surge num contexto de regime de exceção, como expressão de uma política pública de extensão de cobertura e de interiorização das ações de saúde e de saneamento, projetando na figura do auxiliar de saúde um conjunto de atividades que englobava a prevenção de doenças transmissíveis, a educação para a 
saúde, ações de saneamento básico e o atendimento de patologias mais frequentes. O Projeto DEVALE caracteriza-se, numa conjuntura estadual, como a tentativa de colocar em prática as missóes institucionais de extensão de cobertura dos serviços de saúde e de saneamento para uma região do Estado de São Paulo. Seu agente, recrutado na comunidade, deveria desenvolver tanto ações de cunho mais técnico, como atendimento aos indivíduos e famílias, intervenção para a promoção da saúde e monitoramento de grupos ou problemas específicos, como ações mais políticas de organização da comunidade para transformações sociais nas estruturas vigentes, que Silva (2001), identifica como uma dimensão importante e diferenciada da proposta do Projeto DEVALE em relação aos demais.

Por outro lado, identifica-se no Brasil, por iniciativa de organizaçôes religiosas, católicas e algumas outras relacionadas a instituições acadêmicas e organizaçôes não-governamentais, propostas de formação e utilização de agentes comunitários de saúde, como força de trabalho transformadora das relações entre profissionais e classes populares.

David (2001) descreve a experiência de educação popular pela formação de agentes comunitários de saúde, a partir de 1979, patrocinada por uma ordem religiosa católica feminina, ocorrida no município de Petrópolis, Rio de Janeiro. Por volta de 1984, a prefeitura, por intermédio da Secretaria Municipal de Saúde, passou a apoiar a formação dos agentes dessa ordem religiosa. Com a criação e desenvolvimento da Pastoral da Criança, em 1983, e a atuação de seus voluntários, realizando visitas domiciliares a famílias carentes no Brasil, uma grande e vigorosa rede de solidariedade unindo fé e vida foi criada. A Pastoral atua hoje em todos os estados, envolve 230 mil voluntários, 92\% mulheres, a maioria muito pobre. A cada mês, acompanha 1,7 milhão de menores de seis anos, o equivalente a $17,8 \%$ de crianças excluídas do Brasil. Além disso, são atendidas 80 mil gestantes e 32 mil idosos pobres (O GLOBO, 2003).

A Pastoral atua em cinco frentes: cuidados com a gestante, aleitamento materno, vigilância nutricional, soro caseiro e vacinação. Os voluntários plantam hortas comunitárias, fazem programas de rádio e orientam as famílias. Enquanto alguns ensinam como melhorar a nutrição para aproveitamento adequado dos alimentos regionais e alternativos, como farelos e folhas verdes, outros ensinam o soro caseiro para combater a desidratação provocada por diarreias, implementam a utilização de plantas medicinais, cuidam de gestantes, incentivam o aleitamento materno, promovem o conhecimento sobre o desenvolvimento infantil. Dividem-se, ainda, 
em outras atividades, como nos projetos de geração de renda, alfabetização de jovens e adultos, além de colaborarem com outras ações complementares.

A Pastoral da Criança e outras afins têm disseminado um modelo de ação em saúde no Brasil, geradora de vínculos de agentes de saúde com famílias carentes, a partir das quais algumas ações básicas de saúde são desenvolvidas. No entanto, esses agentes, comparados aos atuais agentes comunitários de saúde, agem movidos pela força da fé e da religião, realizam trabalho voluntário e sem remuneração, cuidam de problemas sociais, financeiros, morais e até comportamentais das famílias. $\mathrm{O}$ trabalho que desenvolvem não é gerenciado, supervisionado e avaliado pelo sistema oficial de saúde, embora o influencie e seja por ele influenciado, sendo que em alguns lugares o agente comunitário de saúde trabalha em conjunto com a Pastoral da Criança, da Igreja Católica.

\section{A conjuntura político-econômica e as reformas do Estado}

A redefinição do papel do Estado foi questão central nos anos 90, alcançando vários países, embora já estivesse presente desde os anos 70, tornou-se clara somente a partir da segunda metade da década de 80 .

No Brasil, a questão adquire relevância, tendo em vista a dimensão da presença do Estado na economia nacional. Suas manifestações mais evidentes são a própria crise fiscal e o esgotamento da estratégia de substituição de importações, que se inserem num contexto mais amplo de superação das formas de intervenção econômica e social. Adicionalmente, o aparelho de Estado centraliza e concentra funções e se caracteriza pela rigidez dos procedimentos e pelo excesso de normas e regulamentos.

Desta forma, em meados dos anos 90, surgiu um conjunto de respostas na tentativa de superação da crise, que implicaram em várias medidas envolvendo políticas de ajuste fiscal, reformas econômicas orientadas para o mercado, reforma da previdência social, inovação dos instrumentos da política social e de reforma do aparelho do Estado. No aparelho de Estado inclui-se a estrutura da administração pública em sentido amplo, ou seja, a estrutura organizacional do Estado em seus três Poderes (Executivo, Legislativo e Judiciário) e três níveis (União, estados-membros e municípios). O Estado, por sua vez, é mais abrangente que o aparelho, porque compreende adicionalmente o sistema constitucional legal, que regula a população, nos limites de um território. 
A reforma insere-se dentro do contexto da redefinição do papel do Estado, que deixa de ser o responsável direto pelo desenvolvimento econômico e social pela via da produção de bens e serviços, para fortalecer-se na função de promotor e regulador desse desenvolvimento. Daí a generalização, nos anos 90, dos processos de privatização de empresas estatais, e outro, que ficou conhecido como "publicização", entendido como a descentralização para o setor público não-estatal da execução de serviços que não envolvem o exercício do poder de Estado, mas que devem ser subsidiados por ele, como é o caso dos serviços de educação, saúde, cultura e pesquisa científica. Nessa perspectiva, busca-se o fortalecimento das funções de regulação e coordenação do Estado, particularmente no nível federal, e progressiva descentralização vertical, para os níveis estadual e municipal, das funções executivas no campo da prestação de serviços sociais e de infraestrutura.

Esses conceitos e ideias foram consubstanciados no Plano Diretor da Reforma da Administração Pública Brasileira, que, partindo do diagnóstico de que houve um retrocesso burocrático com a Constituição de 1988 e um encarecimento do custeio da máquina administrativa, propõe uma ampla reforma administrativa, estabelecendo suas principais direções.

Para o aparelho de Estado, fixaram-se diretrizes para tipos de gestão, formas de propriedades, objetivos e recursos humanos dos seus quatro setores: núcleo estratégico, representado pelo governo; atividades exclusivas, compostas pelos serviços que só o Estado pode realizar; serviços não-exclusivos, setor onde atua simultaneamente com outras organizações públicas não-estatais e privadas e, finalmente, o setor de produção de bens e serviços para o mercado, área de atuação das empresas privadas. E para o setor de serviços não-exclusivos, onde a saúde se inclui, foram indicadas a propriedade pública não-estatal e a administração gerencial, sendo a busca da eficiência o seu objetivo maior.

No entanto, algumas questões críticas em relação à implementação dessas medidas na saúde demandam análises mais apuradas já que, independentemente da situação de momento vivenciada pela emergência das reformas, algumas das características das organizações de serviços de saúde merecem ser revisitadas, no sentido de uma apreensão das facilidades ou dificuldades de adoção de um modelo gerencial. As organizações de serviço de saúde podem ser categorizadas como organizações profissionais que controlam seu próprio trabalho e são detentoras de forte influência sobre as decisões administrativas. A intervenção de 
gerentes e administradores é bastante limitada (PIERANTONI, 2001, p. 348).

Nessa conjuntura, assistiu-se ao surgimento, no país, de uma política que colocava o modelo estatutário não como modelo apropriado e único para todos os servidores públicos, mas aplicável apenas àquelas funçôes inerentes ao próprio Estado, do seu núcleo estratégico, reservado aos funcionários que exercem funçôes regulatórias e administrativas de alto nível, como definido na proposta de reforma. De acordo com essa nova concepção, a reforma do Estado modifica a área de recursos humanos do SUS, transformando as relações de trabalho focadas na estabilidade no emprego em relações flexíveis e não-estáveis, favorecendo a proliferação de formas, vínculos e padrões de remunerações diferenciados.

As orientações dessa política, muito embora focalizadas na administração federal, foram promovidas por estados e municípios, em muitas das suas diretrizes e propostas, que tinham aplicabilidade nesses níveis de governo. Nesse cenário de mudanças, em 2002, o Ministério da Saúde chegou a apontar como forma segura de contratação dos agentes comunitários de saúde, considerando-se o perfil desejado para esses profissionais, que as prefeituras adotassem o modelo de parceria com uma organização social, para o desenvolvimento do programa (BRASIL, 2002).

A superioridade do modelo indicado residia nas possibilidades de, simultaneamente, aproximar a sociedade civil da execução de um programa vital para o desenvolvimento da saúde pública no país e da garantia de cobertura dos direitos sociais dos agentes, sem desrespeito aos princípios constitucionais inerentes à administração pública e sem repercussão nos limites impostos pela lei de responsabilidade fiscal.

Já que aspectos relacionados ao perfil do agente são imprescindíveis para o exercício de suas funçóes, e tendo como moldura um cenário de redefinição da estrutura, posição e atividades do Estado e de maior atrelamento às políticas de ajuste econômico do Fundo Monetário Internacional, muitas prefeituras encontraram nos ingredientes desse modelo alternativas e soluções para contratação dos agentes, propiciando sua rápida expansão. Como consequência, cerca de 40\% da força de trabalho do setor público de saúde, o que equivale a aproximadamente 800 mil trabalhadores, encontravam-se inseridos em situação de relações precárias no SUS, nas mais diversas modalidades contratuais: cooperativas, sistemas de bolsas de trabalho, contrato temporário, pagamento por reconhecimento de dívida, prestação de serviços pela CTL, dentre outras (BRASIL, 2003). 
Pesquisa realizada sobre as Modalidades de Contratação de Pessoal no Programa de Saúde da Família no Brasil aponta uma pluralidade de arranjos institucionais que cercam o desenvolvimento do PSF em nosso país, particularmente no que toca ao tema da chamada transição dos sistemas de relações de trabalho e do emprego em nosso país. O PSF, conforme os dados da pesquisa, demonstra, na prática, salários diferentes dos salários de mercado para as diversas categorias profissionais, beneficiando claramente algumas e nem tanto outras, e, ao mesmo tempo, inaugura (ou fortalece) novas formas institucionais de relações de trabalho, mais ou menos flexíveis ou precárias, dependendo da ocupação e das condiçõos e remuneração que pratica (BRASIL, 2002).

No caso dos agentes comunitários de saúde, números estimados para 2003 revelam que dos mais de 180 mil trabalhadores em atividade no país, a grande maioria percebe o equivalente a um salário mínimo, tendo uma inserção precária no sistema, desprotegidos que são em relação à legislação trabalhista (BRASIL, 2003).

\section{O Movimento da Promoção da Saúde}

Particularmente na década de 90 e até os dias de hoje, tem-se observado um renovado e profundo interesse em discutir aspectos de promoção da saúde, termo de uso muito frequente na atualidade, o que não implica necessariamente que a concepção que a encerra seja tão recente.

Leavell e Clark (1965), ao desenvolverem o modelo de história natural da doença e seus três níveis de prevenção, incluíram-na na prevenção primária, como medida destinada a aumentar a saúde e o bem estar geral. A associação da promoção da saúde com a atuação sobre determinantes do meio ambiente e do estilo de vida vieram, segundo Terris (1996), com a segunda revolução epidemiológica; o movimento de prevenção das doenças crônicas.

Já em 1943, a Medicina Social inglesa se preocupava com epidemiologia das doenças crônicas prevalentes, como a úlcera péptica, as doenças cardiovasculares, o câncer e os traumas acidentais. Considerando suas correlações com as condições sociais e ocupacionais, afirmava que elas deveriam ser, em maior ou em menor grau, prevenidas (TERRIS, 1996).

A influência da Medicina Social inglesa se fez sentir profundamente no Canadá, refletindo-se na consagração dos princípios de universalização da assistência médica 
e na centralidade da prevenção e promoção da saúde no sistema canadense. A constatação do papel fundamental dos determinantes gerais sobre as condições de saúde, que vem a qualificar a visão moderna, deve muito à atuação da saúde pública canadense e à sua posterior influência internacional (FERRAZ, 1994).

O Informe Lalonde de 1974, marco inicial da moderna caracterização no Canadá e a primeira declaração teórica abrangente, afirma que a saúde é determinada por um conjunto de fatores agrupáveis em quatro categorias: biologia humana, ambiente, estilo de vida e organização da atenção à saúde. Ao longo dos anos 70 e 80, as evidências da associação entre condiçôes de vida, prosperidade e bom nível educacional se acumularam (MENDES, 1996; TERRIS, 1996). Dessa forma, foram criadas as condiçôes para organização da primeira Conferência Internacional em Promoção de Saúde, em 1986, em Ottawa, no Canadá.

A promoção da saúde foi conceituada como o processo de capacitação da comunidade para atuar na melhoria de sua qualidade de vida e saúde, incluindo maior participação no controle deste processo. A Carta de Ottawa assume que a equidade em saúde é um dos focos, cujas açóes objetivam reduzir as diferenças no estado da população e no acesso a recursos diversos para uma vida mais saudável (BUSS et al., 1988). Com a evolução do movimento na América do Norte, surgiu o Movimento Cidades Saudáveis, encampado pelo OMS a partir de 1986, após a experiência ocorrida em 1984, em Toronto, no Canadá.

A OMS considera uma cidade saudável aquela em que os dirigentes municipais enfatizam a saúde de seus cidadãos numa ótica ampliada de qualidade de vida. $\mathrm{O}$ movimento se difundiu em inúmeras cidades do mundo e tornou-se um projeto estruturante e moderno, tendo sido também incorporado como estratégia pelo movimento de municipalização da saúde no Brasil (MENDES, 1996; FERRAZ, 1994, 1996; BUSS et al., 1988).

A promoção da área não concerne exclusivamente ao setor de saúde, nem a um único profissional de saúde. Ela é resultado de ações intersetoriais, agindo nos determinantes gerais e da qualidade de vida. Para se promover a saúde, devese ir além do cuidado e colocar em prática técnicas para tornar mais eficientes à comunicação e à mobilização da comunidade.

Como as profissões específicas do setor estão tradicionalmente mais voltadas para o tratamento das doenças, ou para facetas particulares da saúde, como a nutrição, dentre outras, espera-se que o agente comunitário tenha seu foco 
na saúde, integrando os conhecimentos relativos às diversas profissões e que confluem para sua promoção. Os atributos e habilidades que deveria possuir um profissional de saúde, atuando na linha da promoção, em geral não são reconhecíveis nos existentes, que tradicionalmente não atuam nesse entorno ampliado que se tornou seu campo de trabalho, não extravasando os limites da unidade básica de saúde.

Nessa perspectiva, o agente comunitário constitui-se, por suas características especiais, em um recurso humano central e estratégico para a possibilidade de implementação de açôes de promoção e de novas formas de perceber e praticar a atenção à saúde, envolvendo as pessoas, seus conhecimentos e entornos.

\section{Conclusão}

A Constituição Brasileira de 1988 inscreve a saúde como direito de cidadania, e a criação do Sistema Único de Saúde inaugura dois movimentos importantes em sua política no Brasil: a passagem de um modelo de seguro social para um modelo de seguridade social; e de um modelo centrado na medicina curativa, para um modelo de atenção pautado na integralidade, conforme requerido pelo movimento da Reforma Sanitária.

No entanto, depois da regulamentação dos dispositivos constitucionais para a saúde, o que só ocorreu em 1990, já no cenário da contra-reforma, a ausência de um acordo relacionado à estrutura inicial do SUS acarretou resistência de toda ordem na fase de implementação. Acrescentem-se, no contexto dessa década, a política de ajuste imposta pelo governo federal, com exigência de encargos extras para estados e municípios, aprofundando ainda mais as desigualdades sociais e regionais, gerando grandes iniquidades. As políticas sociais e de saúde perderam sua dimensão integradora, no âmbito nacional, regional e estadual, gerando uma visão focalista, na qual o local é tido como único espaço capaz de dar respostas mais eficientes e consoantes às necessidades da população. Voltamos a uma visão comunitária, segundo a qual as pessoas e as famílias passam a ser as responsáveis últimas por sua saúde e bem-estar.

Nessa conjuntura, o agente comunitário de saúde é o agente nuclear para viabilizar o apoio, a implementação e o desenvolvimento de açôes básicas voltadas para a comunidade, de forma a expandi-las e a fortalecê-las em nível nacional. 


\section{Referências}

ASSUNÇÃO, R.S. A visita domiciliar realizada pelo agente comunitário de saúde no contexto do Programa de Saúde da Família. 2000.45f. Monografia (Curso de Especialização em Saúde da Família) - Faculdade de Medicina, Universidade Federal de Minas Gerais, Belo Horizonte, 2000.

BODSTEIN, R.C. de A.; FONSECA, C.M. O desafio da Reforma Sanitária: consolidação de uma estrutura permanente de serviços básicos de saúde. In: COSTA, N.R. et al. (Org.). Demandas Populares, Políticas Publicas e Saúde. Vol. 1, Petrópolis: Vozes, 1989. p. 67-90.

BRASIL. Ministério da Saúde. Ministério da Educação e Cultura. Programa de Preparação Estratégica de Pessoal de Saúde - PREPS. Brasília, OPAS, 1976.

Ministério da Saúde. Secretaria de Política de Saúde. Departamento de Atenção Básica. Modalidades de Contratação de Agentes Comunitários de Saúde: um pacto tripartite. Brasília: Ministério da Saúde, 2002.

. Ministério da Saúde. Secretaria de Gestão do Trabalho e da Educação na Saúde. Departamento de Gestão e da Regulação do Trabalho em Saúde. Relatório. Seminário Nacional sobre Politica de Desprecarização das Relaçôes de Trabalho no SUS. Brasília: Ministério da Saúde, 2003.

Ministério da Educação. Ministério da Saúde. Referencial Curricular para Curso Técnico de Agente Comunitário de Saúde. Área Profissional Saúde. Brasília: Ministério da Saúde, 2004.

BUSS, P.M. Uma introdução ao conceito de promoção da saúde. In: CZERESNIA, D.; FREITAS, C.M. (Org.). Promoção da Saúde: conceitos, reflexões, tendências. Petrópolis: Vozes, 2002. p. 15-38.

DAL POZ, M. R. O agente comunitário de saúde: algumas reflexões. Interface: Comunic, Saúde, Educ, v. 6, n. 10, p. 75-94, 2002.

DAVID, H.M.S. De povo de Deus à institucionalização domesticadora: mudanças e passagens em duas décadas de educação popular com agentes comunitários de saúde. In: VASCONCELOS, E. M (Org.). A saúde nas palavras e nos gestos. Reflexôes da Rede Educação Popular e Saúde. São Paulo: Hucitec, 2001. p. 217-235.

ESCOREL, S. Reviravolta na Saúde: origem e articulação do movimento sanitário. 1987. Dissertação (Mestrado em Saúde Pública) - Escola Nacional de Saúde Pública, FIOCRUZ, Rio de Janeiro, 1987.

FERRAZ, S.T. Bases conceituais de promoção da saúde. Brasília: OPS, 1994.

LABRA, M.E. Política e saúde no Chile e no Brasil: contribuições para uma comparação. Ciência \& Saúde Coletiva, v. 6, n. 2, p. 361-376, 2001. 
LALONDE, M.A. A New Perspective on the Health of Canadians. In: OPAS. Promoción de la Salud: una antología. Washington, D.C.: OPAS, 1996.

LEAVELL, H.R.; CLARCK, E.G. Níveis de aplicação de Medicina Preventiva. In:

Medicina Preventiva. São Paulo: McGraw Hill do Brasil, 1976. p. 11-36.

LIMA, C.R.M. Reforma do Estado e Política de Saúde: discussão da agenda do Banco Mundial e da crítica de Laurell. Saúde em Debate, n. 49-50, p. 34-43, mar. 1996.

MENDES, E.V. Uma agenda para a saúde. São Paulo: Hucitec, 1996.

NORONHA, J.C. de; SOARES, L.T. A política de saúde no Brasil nos anos 9. Ciência e Saúde Coletiva, Rio de Janeiro, v. 6, n. 2, p. 445-450, 2001.

O GLOBO. Rio de Janeiro, 28 de dezembro de 2003, Caderno Especial, p. 6.

PIERANTONI, C.R. As reformas do estado, da saúde e recursos humanos: limites e possibilidades. Ciência \& Saúde Coletiva, Rio de Janeiro, v. 6, n. 2, p. 341-360, 2001.

PIRES, D. O saber e as práticas de saúde no Brasil e sua apropriação pela Medicina e pela Enfermagem Institucionalizadas. 1988259 f. Dissertação (Mestrado em Sociologia Política) - Universidade Federal de Santa Catarina, Florianópolis, 1988.

SANTOS, R.C.N. A História do Projeto Montes Claros. In: FLEURY, S. (Org.). Projeto Montes Claros: a utopia revisitada. Rio de Janeiro: Abrasco, 1995.

SILVA, J.A. O agente comunitário de saúde do Projeto Qualis: agente institucional ou agente de comunidade? 2001. Tese (Doutorado em Saúde Pública) - Faculdade de Saúde Pública, Universidade de São Paulo, São Paulo, 2001.

SOUZA, M.F. de. Agentes Comunitários de Saúde: choque de povo. São Paulo: Hucitec, 2001. SILVA, J.A.; DALMASO, A.S.W. Agente comunitário de saúde e suas atribuições: os desafios para os processos de formação de recursos humanos em saúde. Interface: Comunic, Saúde, Educ, v. 6, n. 10, p. 75-96, fev. 2002.

TERRIS, M. Conceptos de la promoción de la salud: dualidades de la teoría de la salud pública. In: . Promoción de la Salud: una antología. Washington: Opas, 1996. (Publicação Científica 557).

VAN STRALEN, C.J. Do Projeto de Montes Claros para o Sistema Único de Saúde: o hiato entre ideologia e realizações práticas. In: FLEURY, S. (Org.). Projeto Montes Claros. a utopia revisitada. Rio de Janeiro: Abrasco, 1995. p. 165-191. 


\section{Abstract}

Community health agents: Brazilian experiences and models

This paper is part of the doctoral thesis Profile of Community Health Workers in the region of Juiz de Fora, $M G$, and presents a profile of Community Health Agents (CHA) from the perspective of family health teams, of users and themselves. It discusses the models and experiences on the CHA practiced in Brazil before the initiative of Ceará State, in the 1980's. It contextualizes the movements for the successful reform of the CHA, which characterize a central human resource and strategic for the implementation of health promotion actions, enabling the development of basic community-related actions. It shows that community health agents are a key factor to enable the support, implementation and development of basic community-related actions, to expand them and strengthen them nationwide, but health promotion concerns not only the sector itself nor a single health professional. It is the result of inter-sectoral actions acting in general and quality of life determinants.

Key words: community health agent; health agent; health assistant. 